\title{
Failure Analysis at the National Transportation Safety Board
}

T he National Transportation Safety Board (NTSB) is an independent government agency with one primary objective: to improve transportation safety. To achieve this goal, investigations are conducted around the world in all modes of transportation, including aviation, railway, pipeline and hazardous materials, highway, and marine. The primary product resulting from the investigations is the safety recommendation, which is a document, submitted to other agencies responsible for regulating and enforcing transportation safety, to legislatures that create transportation laws, and to associations and companies that operate transportation systems. The NTSB also provides support for victims' families and adjudicates appeals by airmen and mariners on US Department of Transportation license actions. The NTSB has five board members who are appointed by the President and approved by the Senate. The NTSB reports directly to congress and is totally independent from other government agencies.

By federal law, the NTSB has first priority in the investigation of an accident. Certain parties may be invited to participate in the investigation. A party is defined as a person, company, agency, or association whose employees, functions, activities, or products are involved in the accident and who can provide suitable qualified technical personnel to actively assist in the investigation. Party personnel must be responsive to the direction and objectives of the NTSB investigation, or risk losing party status. No lawyers or claims adjusters may participate as party representatives. By law, the FAA

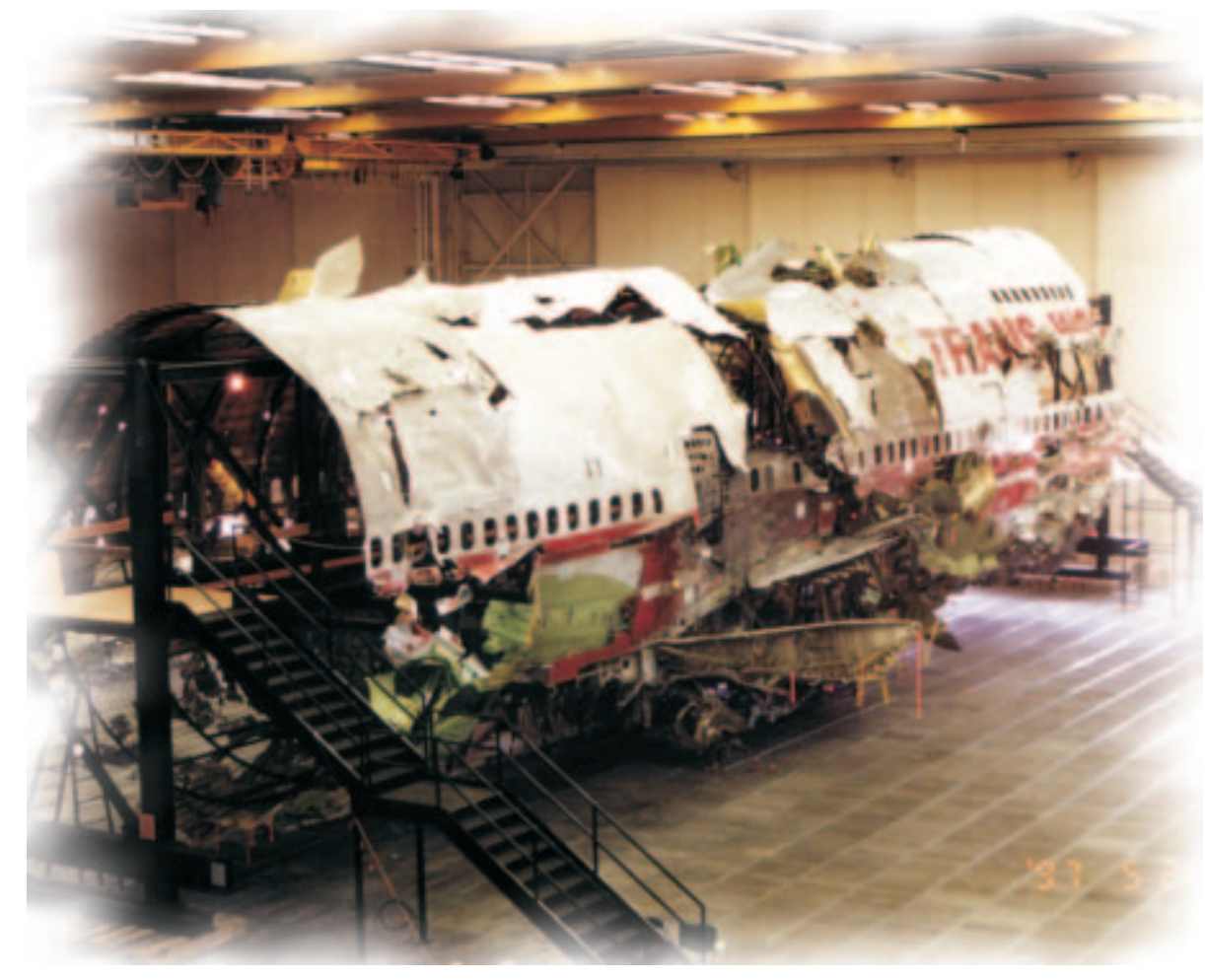

Fuselage reconstruction from the investigation of TWA Flight 800 (Atlantic Ocean off Long Island, N.Y., 17 July 1996).

is always a party to an aviation investigation.

An NTSB accident investigation involves several phases. The first phase is the initial examination, where evidence is collected from the scene of the accident. At all times, the NTSB has a "Go-Team" ready to be dispatched to a major accident site within two hours of notification. The next phase, which may occur concurrently with the first phase, involves additional fact finding, where further evidence and background information is gathered at locations other than the accident scene. Data gathered in this phase may include radar data, maintenance records, flight data and cockpit voice recordings, witness interviews, materials laboratory examinations, and more. After facts are gathered, the investigation enters an analysis phase, where the facts are assembled to support or refute possible accident scenarios. Next, the findings are formulated and a report is written, which includes the safety recommendations. Finally, the report is presented to the board members for approval and publication.

Coordinating the efforts of the parties and investigators in a major investigation requires planning and organization. During the on scene investigation, organizational meetings and daily progress meetings are used to coordinate and focus the investigation. The NTSB investigatorin-charge (IIC) leads the efforts. Under the direction of the IIC, groups are established to investigate various aspects of the accident. The group leader is an NTSB specialist who is responsible for leading the 


\section{Failure Analysis at the National Transportation Safety Board (continued)}

examination in a specific area, such as structures or power plants in an aviation accident, or rail or signals in a railway accident.

A variety of resources are available to assist the investigators in gathering and analyzing the facts. Specialists in different fields, such as human factors, weather, aircraft performance, and fire, are available for consultation. The materials laboratory and recorder laboratories are also available, staffed by experts in their field. The investigator can access an extensive accident database, maintained by the NTSB, which provides information to study historical trends. Industry cooperation and contractual support are additional resources available to investigators.

Investigators can submit failed components to the materials laboratory for examination, or they may request the on-scene presence of a materials engineer or metallurgist. After the on-scene examination, selected components are sent to the laboratory for further examination. Laboratory equipment for viewing component features and microstructures are available, including stereoscopes, a metallograph, and a scanning electron microscope equipped for energy-dispersive and wavelength-dispersive spectroscopy. Standard equipment for metallographic preparation is also available. Hardness testing and some nondestructive testing is also performed in the laboratory. Mechanical testing, other than hardness testing, is completed at an independent laboratory or at a party's facility under NTSB supervision. The results of the materials laboratory examination are summarized in a report, which is

(continued on page 12)

\section{NTSB Materials Laboratory Involvement in Major Investigations}

T he National Transportation Safety Board simultaneously investigates major accidents in different modes of transportation at any time. The services of the materials laboratory are available to support any of those investigations. The following describes some of the materials laboratory involvement in several major investigations from the rail, pipeline and hazardous materials, and aviation transportation modes. As these were ongoing investigations at the time this article was written, the information provided in this article is restricted to factual information that is publicly available. The analyses, determination of probable causes, and issuance of any safety recommendations will be undertaken in the future, and the National Transportation Safety Board will publish the results.

\section{Rail: Derailment in Carbondale, Kan.}

On 15 March 2000, a National Railroad Passenger Corporation (Amtrak) train traveling from Chicago, Ill., to Los Angeles, Calif., derailed in Carbondale, Kan. There were no fatal injuries among the 139 passengers and $16 \mathrm{crew}$. After the initial on-scene investigation, 12 pieces of rail were sent to the materials laboratory for examination. Ten of the pieces were recovered from the point of derailment (POD). All pieces of rail were from the inside (low side) of a curve.

Examination of the rail included optical and scanning electron (SEM) microscopy and energy dispersive $\mathrm{x}$-ray spectroscopy (EDS) of fracture surfaces and microstructures. Crack lengths were measured where visible to the exterior of the rail. Ultrasonic testing was performed near the crack ends to verify that no additional internal crack length was present. In addition, transverse cuts were made in multiple locations, and the profiles at those locations were compared to design specifications. A chemical analysis was performed on rail from the POD. Also, grinding marks, observed on the field and gage side of the head, were profiled in one location.

A transverse cross section of one of the sections from rail recovered at the POD is shown in Fig. 1. The dark line in the figure is the rail profile as specified in the manufacturing drawing. The vertical head loss at this location was 0.329 in. $(8.36 \mathrm{~mm})$. Considerable widening and dropping of the head on the gage side was noted. As shown by arrow $\mathrm{V}$, a vertical crack was observed in the head of the rail (vertical split head). The crack was at least 233 in. (591 cm) long, continuing through the entire lengths of most pieces recovered from the POD, and appeared to continue further to the west. The laboratory did not receive the piece of rail that presumably contained the west end of the crack.

The vertical fracture surface visible on a piece of rail recovered from the POD appeared rough, light gray in color, with some orange color; features consistent with overstress fracture with short term exposure to an oxygen-rich environment. Using chevron markings, the fracture origin of this portion of the vertical fracture was traced to an area shown in Fig. 2. The origin is located approximately at the right dashed line, and unlabeled arrows 
indicate the direction of crack propagation. (Transverse cuts were made at the locations indicated by the dashed lines to facilitate SEM, EDS, and microstructural examination of the origin area.) The chevron pattern appeared to emanate from stripe-like features (longitudinally aligned inclusions) indicated by arrows a. Examination of the stripe-like features using energy dispersive $\mathrm{x}$-ray spectroscopy (EDS) produced peaks of aluminum, which were not present in the EDS spectra in other areas.

\section{Pipeline and Hazardous Materials: Gasoline Spill in Greenville, Texas}

On 9 March 2000, an Explorer Pipeline Company pipeline failed near Greenville, Texas, releasing approximately 12,000 barrels of gasoline. After the on-scene portion of the investigation was completed, an $8.5 \mathrm{ft}$. $(2.6 \mathrm{~m})$ section of the 28 in. $(71 \mathrm{~cm})$ diameter pipe was sent to the materials laboratory for examination. Examination of the section of pipe included optical and scanning electron (SEM) microscopy of the fracture surfaces as well as metallographic examination of cross-sections through the fracture surface.

An overall view of the section of pipe received by the mater-

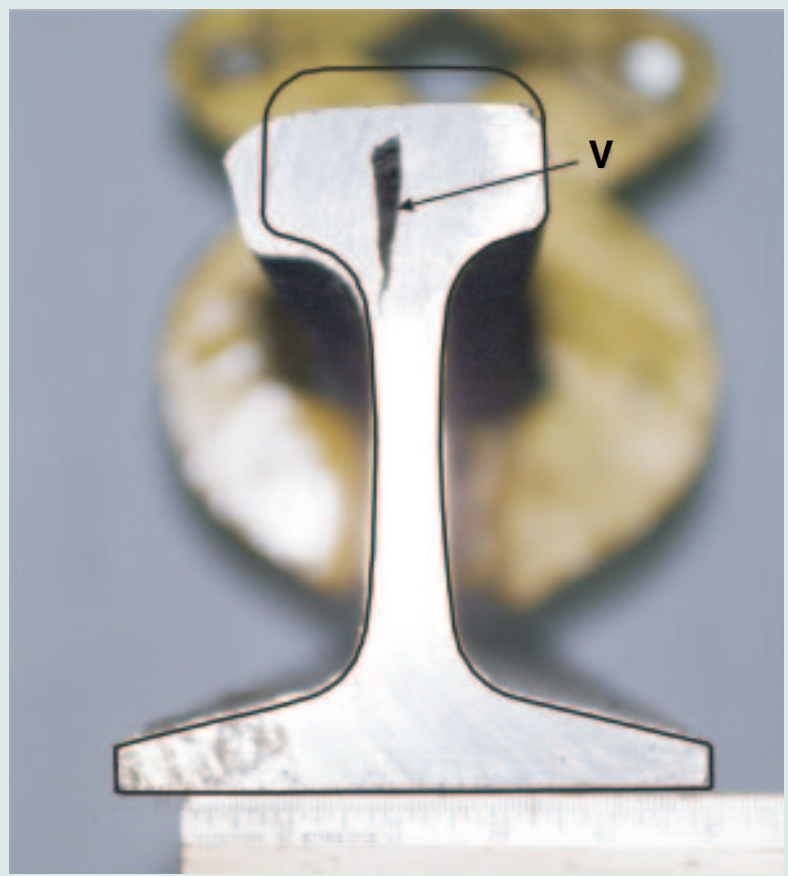

Fig. 1 Transverse cross section of the rail at the POD. The dark line is the specified rail profile as manufactured. Arrow $V$ indicates a vertical crack in the rail head. ials laboratory is shown in Fig. 3. The section consisted of portions of two pieces of pipe joined by a girth weld located $17.9 \mathrm{in} .(45.5 \mathrm{~cm})$ north of the south cut end. A $50.4 \mathrm{in}$. $(128 \mathrm{~cm})$ fracture was present north of the girth weld, where the center of the crack corresponded approximately to the region indicated by bracket a in Fig. 3. At its widest, the gap between the fracture surfaces was $6.8 \mathrm{in} .(17 \mathrm{~cm})$. Along the center 15 in. $(38 \mathrm{~cm}$ ) length of the crack (region a), the crack was located at the toe of a longitudinal seam weld.

A portion of the fracture surface in region a is shown in Fig. 4. From the outer to inner edge of the fracture surface, three different areas were observed. Unlabeled arrows indicate the smoothly curving boundary of the first area, the dark region. The second area, appearing light gray in Fig. 4, also had a smoothly curving boundary, indicated by the dashed line. Crack arrest lines were observed in the second area, an indication of fatigue. The third area, adjacent to

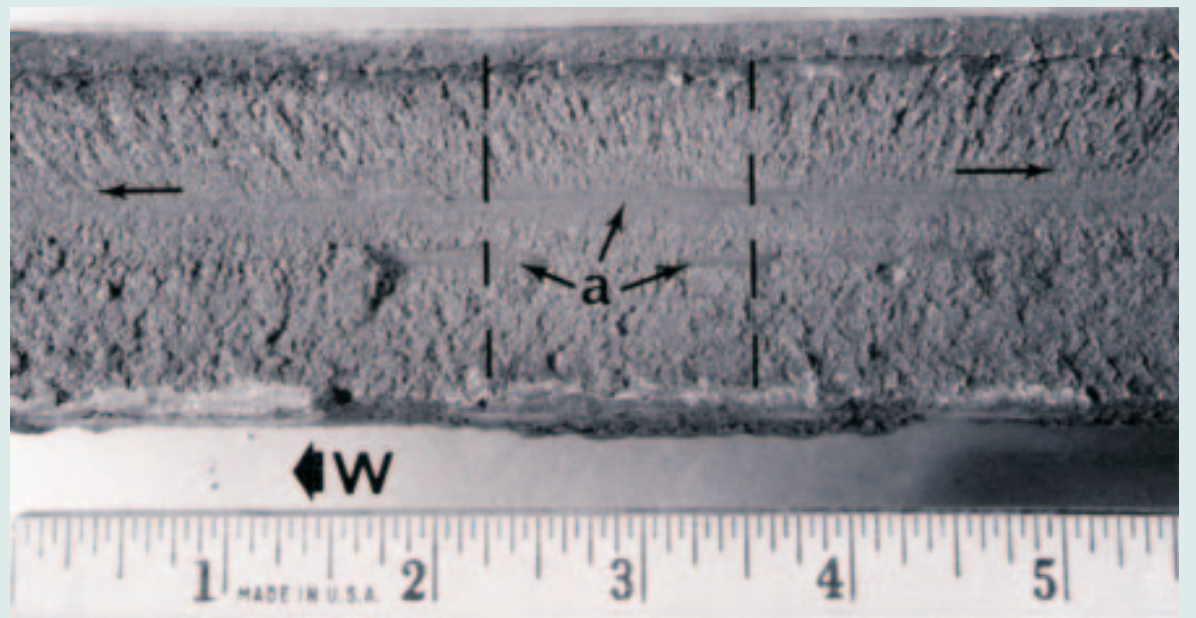

Fig. 2 A view of the fracture surface of the vertical crack at the POD. Transverse cuts were made at the dashed lines, where the origin is located approximately at the right line. Unlabeled arrows indicate the direction of crack propagation. Fracture features emanated from longitudinally aligned inclusions rich in aluminum, indicated by arrows $a$. the inner edge of the fracture surface, formed an angle of approximately $45^{\circ}$ to the circumferential direction, an indication of ductile overstress. Viewed at higher magnification using SEM, fracture features in area 1 were obliterated by corrosion. The fracture features in region 2 were relatively smooth, and striations were observed, typical of fatigue. In region 3, dimple features were observed, typical of ductile overstress.

A layered coating was present on the pipeline. The inner layer of the coating was a black tar-like substance adjacent to the pipe outer

(continued on page 10) 


\section{NTSB Materials Laboratory Involvement in Major Investigations}

surface. The outer layer was a wrapped fibrous material. As indicated by arrows $\mathrm{c}$ in Fig. 3, meandering gaps (cracks) in the coating were observed near the top of the pipeline. The cracks ranged in width up to approximately $2.5 \mathrm{in} .(6.4 \mathrm{~cm})$, exposing the outer surface of the pipeline. In areas away from the cracks, the coating appeared to be well bonded and was difficult to remove from the pipeline surface. Longitudinally oriented wrinkles in the coating were observed on the sides and lower surfaces along the entire length of the submitted section of pipeline.

Corrosion pits were observed on the outer surface of the pipe section in locations where the coating was cracked. In areas where some coating was removed in the materials laboratory, no corrosion was observed. The corrosion pits were generally isolated except near region a, where areas of continuous corrosion pits were observed directly adjacent to the fracture.

\section{Aviation: Crash of Alaska Airlines Flight 261}

On 31 January 2000, a McDonnell Douglas MD-83 airplane crashed off the California coast while en route from Puerto Vallarta, Mexico, to San Francisco. All 83 passengers and 5 crewmembers were fatally injured and the aircraft was destroyed. A plot of the altitude readings from the transponder radar data for the final 14 minutes of the flight is shown in Fig. 5. At the time corresponding to the initial descent, the autopilot disengaged. Simultaneously, the horizontal stabilizer trim moved to the full nose down position in six seconds, remaining in that position until the final upset. As recorded on the cockpit voice

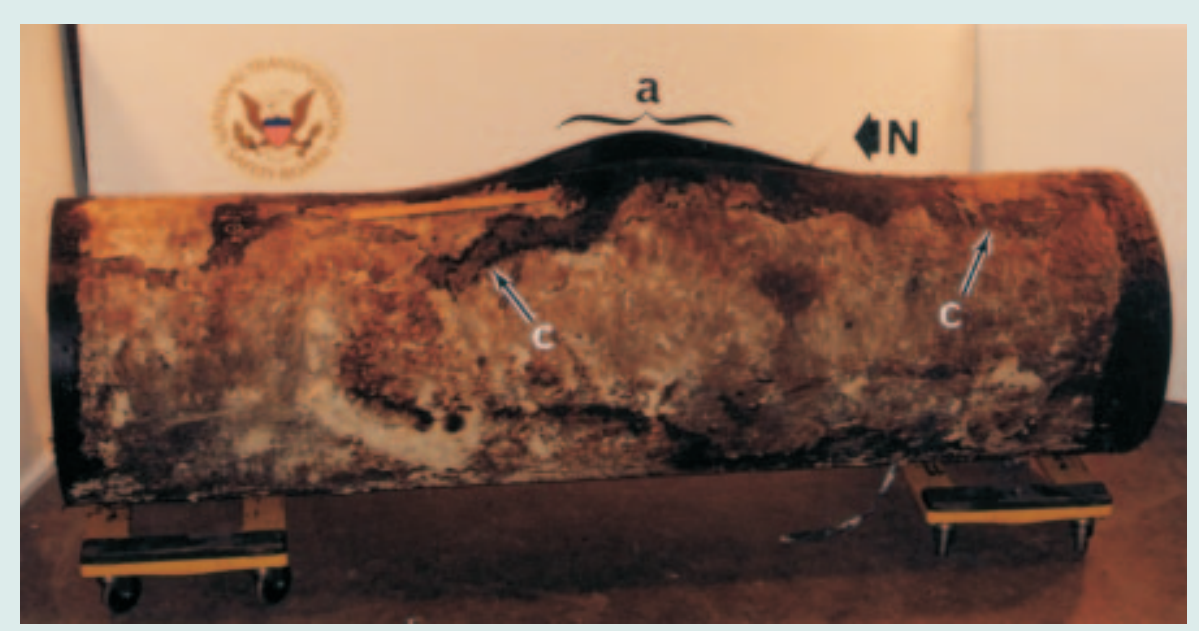

Fig. 3 An overall view of the submitted section of pipeline. Bracket a indicates the center region of the crack, and arrows $c$ indicate cracks in the coating.

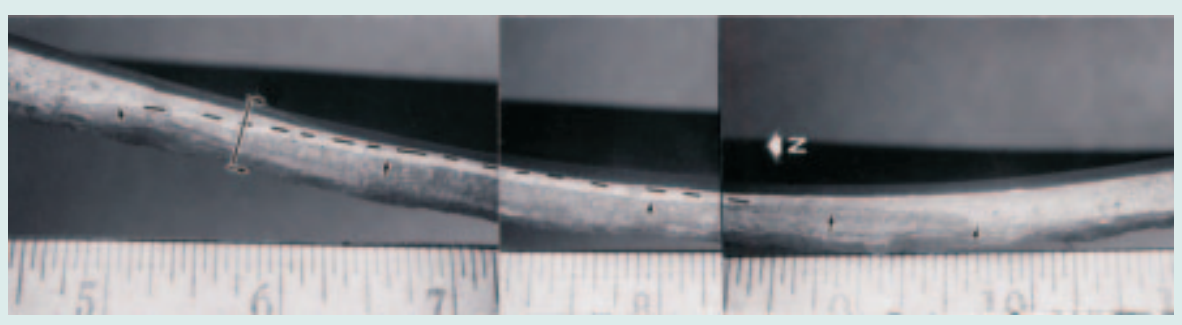

Fig. 4 A view of a portion of the fracture surface in region a. Unlabeled arrows indicate the boundary of the dark region, and a dashed line indicates the boundary of the light gray region where crack arrest lines were observed.

recorder, the crew commented that they were not able to maintain vertical control. After about a minute of rapid descent at more than three times the normal rate of descent, the aircraft leveled off in what may be characterized as controlled flight. After approximately nine minutes of controlled flight, the aircraft pitched over in its final descent, dropping from $17,900 \mathrm{ft}$. $(5456 \mathrm{~m})$ in about a minute.

With assistance from the United States Navy, approximately $90 \%$ of the aircraft was recovered from a depth of about $700 \mathrm{ft}$. $(213 \mathrm{~m})$. Among the recovered components were parts of the jackscrew assembly, including the jackscrew with an internal torque tube, the gimbal nut, and the upper and lower mechanical stops.
In the MD- 80 series aircraft design, the jackscrew is connected to the horizontal stabilizer and controls movement of the horizontal stabilizer. A torque tube, located at the center of the hollow jackscrew, has a threaded end with a nut and washer that are tightened against the lower end of the jackscrew. A trim motor, activated by cockpit controls, produces rotation of the jackscrew within a gimbal nut that is attached to the vertical fin. Thus, longitudinal movement of the jackscrew relative to the gimbal nut is generated with corresponding movement of the horizontal stabilizer. Upper and lower electric stops set limits on the jackscrew movement. Outside of those limits, upper and lower mechanical stops provide additional 
limits to the jackscrew movement. The mechanical stop assemblies are attached to upper and lower splined regions on the jackscrew with positions set by alignment pins. The mechanical stops are secured to the screw by tangential (clamp) bolts that pass through circumferential grooves in the splined regions.

The jackscrew and gimbal nut were recovered separately. Views of the recovered jackscrew and gimbal nut are shown in Fig. 6 and 7, respectively. The lower threaded end of the torque tube and the torque tube nut and washer were separated from the remainder of the jackscrew assembly and were not recovered at the time this article was written. The lower mechanical stop was also separated from the jackscrew and was recovered separately. Strips of material, consistent in composition with the gimbal nut threads, were wrapped around the threaded portion of the jackscrew as shown in Fig. 6. The threads of the gimbal nut were missing from the gimbal nut interior.

Multiple damage features, indicative of contact with another object, were observed on the upper surface of the lower mechanical stop, shown after cleaning in Fig. 8. These features ranged from light marks in the primer to severe dents and deformation of the metal. Based on relative locations and feature shapes, features labeled a to $\mathrm{j}$ in Fig. 8, were all consistent with contact between the upper surface of the mechanical stop and various portions of the lower end of the gimbal nut, shown in Fig. 7. In general, rotational scoring was observed within the damage areas. Shown in Fig. 8, raised lips of metal were observed at the edge of location $b$ where it mated with the damage of location a, indicating that damage associated with location a occurred before the damage at location $b$.

Damage to the spline teeth was also observed on the lower mechanical stop. Rotational stripping was present on different circumferential regions of the upper and lower portions of the spline teeth. (Stripping was defined as being present in any region where individual spline teeth were nearly indistinguishable from each other.) The middle portion of the splines, approximately 0.25 in. (6.4 $\mathrm{mm}$ ) wide, was damaged but not stripped at any circumferential location. This middle portion corresponds to the groove in the jackscrew splines

(continued on page 12)

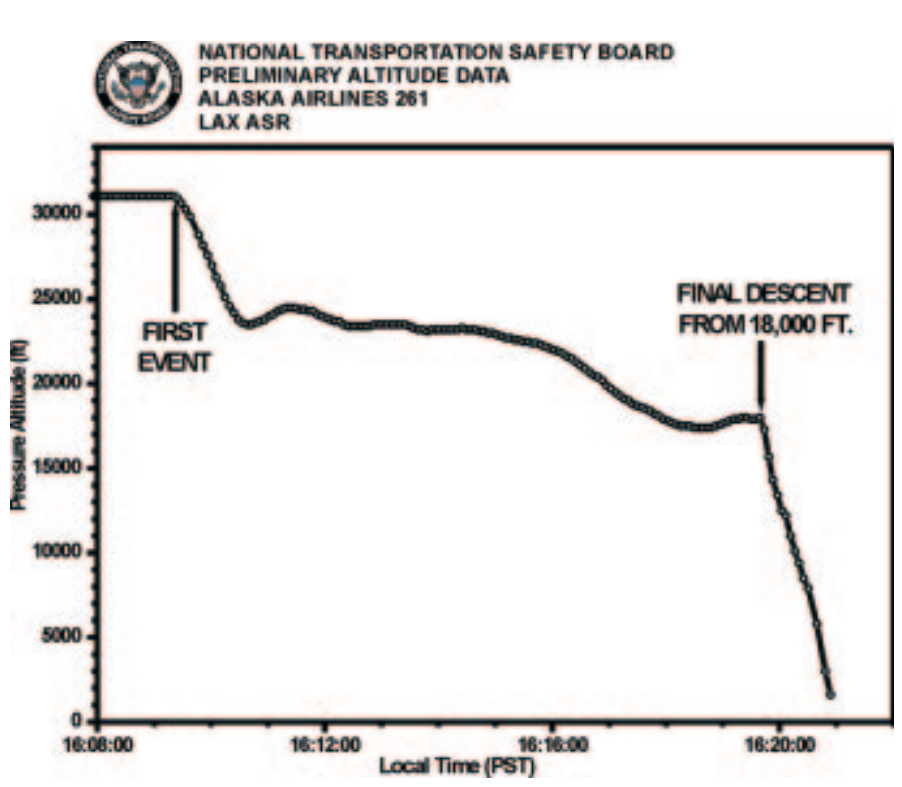

Fig. 5 A chart of the preliminary altitude data for the final minutes of Alaska Airlines flight 261.

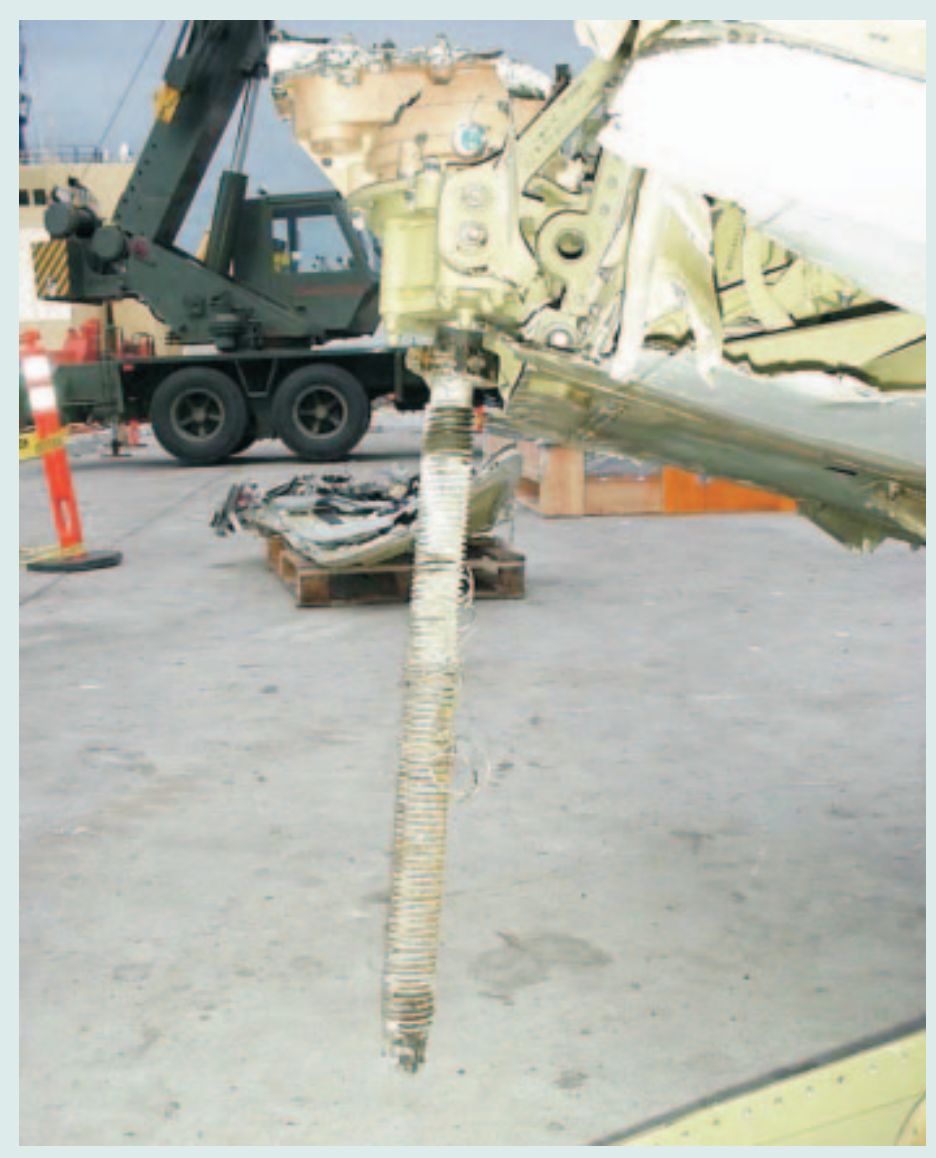

Fig. 6 A view of the recovered jackscrew. 


\section{NTSB Materials Laboratory Involvement in Major Investigations (continued)}

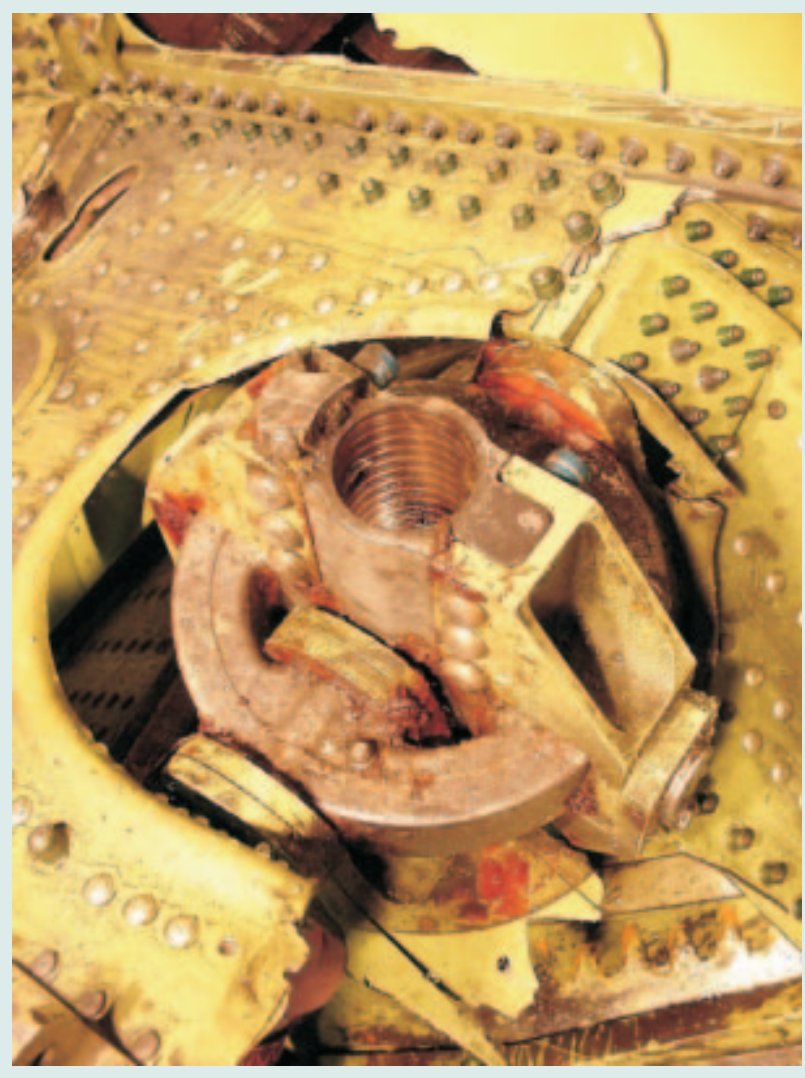

Fig. 7 A view of the recovered gimbal nut.

for the stop clamp bolt. The circumferential scoring marks associated with the stripped areas of the spline teeth were slightly offset from directly circum-

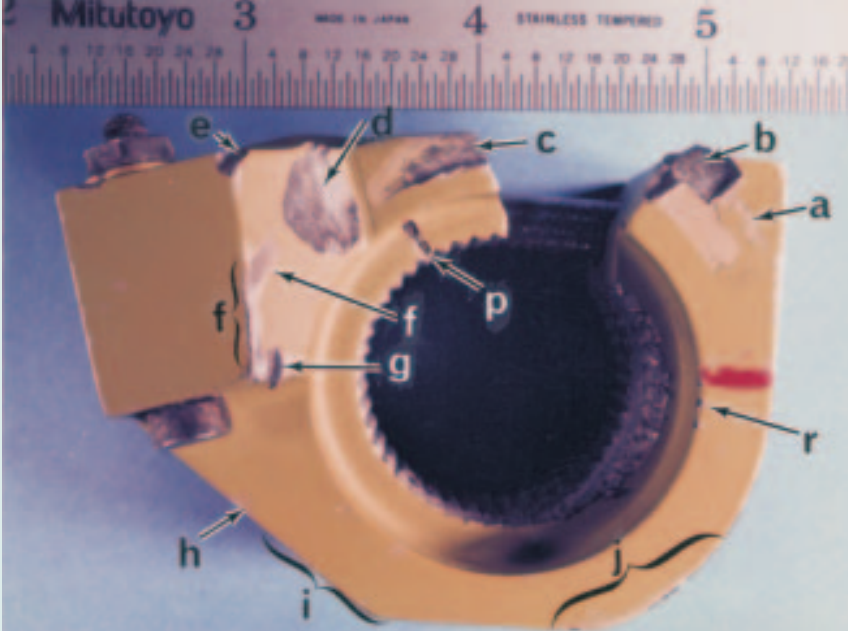

Fig. 8 The upper surface of the lower mechanical stop viewed from above. Arrows a through $j$ and $r$ indicate locations of damage on the upper surface. Arrow p indicates a through hole for an alignment pin.

ferential. The stripping pattern and offset circumferential marks were consistent with the lower stop being at two or more skewed angles to the splines of the jackscrew during stripping.

The materials laboratory involvement in this investigation is continuing, and complete documentation of the observations will be detailed in several laboratory reports.

\section{Failure Analysis at the National Transportation Safety Board (continued)}

used by the investigator in the factfinding phase.

The NTSB materials laboratory staff consists of six engineers and metallurgists, one technician, and the division chief, and a huge variety of components and failures are examined. The component may be as small as a filament from a light bulb, which may be used to determine if the light was on at the time of impact. Or the component may include the entire fuselage of a Boeing 747-131, which was examined to determine the breakup sequence for TWA flight 800 . Examination of deformation and markings on the gimbal nut and lower stop of the jackscrew assembly from Alaska Airlines flight 261 provided information for that ongoing investigation (see sidebar starting on page 9). Fracture surfaces containing fatigue regions are commonly observed in a variety of components, from crankcase studs to turbine disks, made from nearly any structural material, including aluminum alloys, steels, and titanium alloys. Non-metallic components, such as degraded rubber gaskets or delaminated composite rotor blades, are also examined in the laboratory. The combined failure analysis experience among the materials laboratory staff is extensive, and failure analysis investigations conducted by the materials laboratory have made significant contributions to the success of many NTSB investigations.

Since its inception in 1967 , the NTSB has investigated over 100,000 aviation accidents and thousands of surface transportation accidents, developing a reputation for impartiality and thoroughness. 


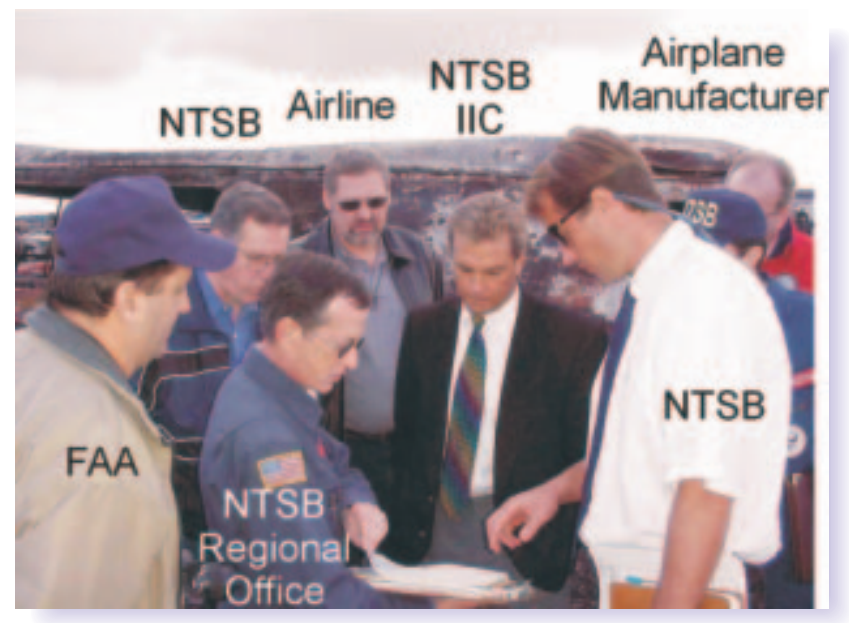

On-scene investigation showing interaction between IIC, group leaders, and party representatives. (Photo: George W. Black, Jr.)

In that time, almost 10,000 recommendations have been made to more than 1,250 recipients, with more than 80 percent of the recommendations adopted by those in a position to affect change. Many safety features in airplanes, automobiles, pipelines, trains, and marine vessels were sparked by NTSB recommendations, and as a result, we are all safer.

\section{Acknowledgment}

This article is based on a presentation prepared by George W. Black, Jr. and presented by Matthew R.

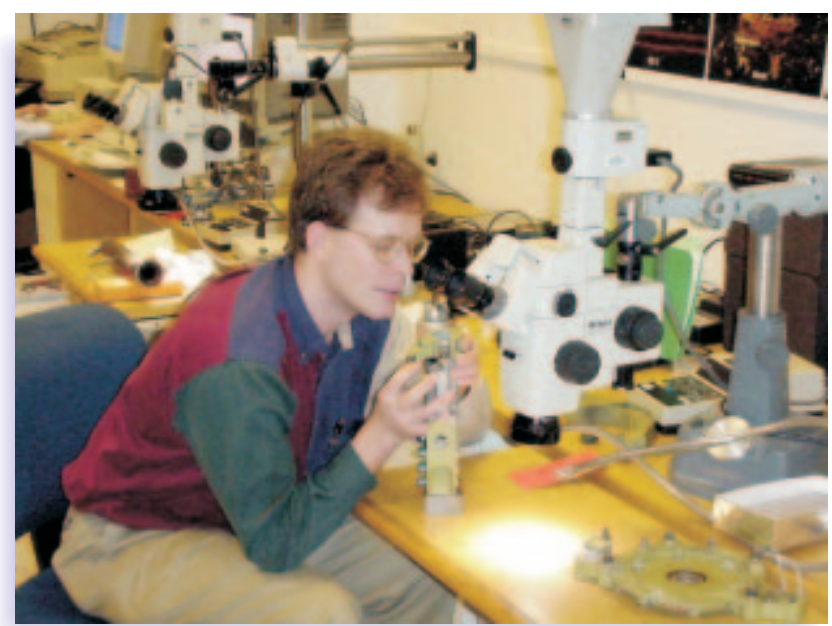

Visual examination of the gimbal nut and lower stop from the jackscrew assembly from Alaska Airlines Flight 261,

Point Mugu, Calif., 31 January 2000. (Photo: George W. Black, Jr.)

Fox at the ASM conference, Failure Prevention Through Education: Getting to the Root Cause, 23-25 May 2000, Cleveland, Ohio. The author gratefully acknowledges comments and suggestions provided by James $\mathrm{F}$. Wildey, II.

Matthew R. Fox, Ph.D., materials engineer, Materials Laboratory Division, National Transportation Safety Board, 490 L'Enfant Plaza East, SW, Washington, D.C. 20594; e-mail: foxm@ntsb.gov 